\title{
Study on the Sports Activities of Rural Children in the Yi Area
}

\section{A Case Study of Leshan City}

\author{
Lu Changchun ${ }^{1,}$, Jiang Hongying ${ }^{2, b}$ \\ ${ }^{1}$ School of Physical Education, Leshan Normal University, Leshan 614004,China \\ ${ }^{2}$ Department of physical education, The engineering and technology College of Chengdu University \\ of Technology, Leshan 614004,China \\ aluchangchun@126.com, bjianghongying@163.com
}

Keywords: Leshan district; Rural children; Sports activities

\begin{abstract}
Through field surveys and other research methods, this article analyzes the present situation of rural preschool children sports activities in the leshan yi nationality region. It was found that rural children's sports activities in the region were carried out not well at all: the lack of the content, the result of children's sports activities could not reach the requirements of the physical and mental health development; sports education goal is not clear. This paper put forward corresponding countermeasures based on the actual purpose to enrich teaching contents, improve teaching means to promote health of body and mind development, and provide a reference for yi region rural preschool physical education.
\end{abstract}

\section{Introduction}

It is put forward in the national medium and long-term education reform and development plan outline (2010-2020) that "basic universal pre-school education, clear the government responsibility, focus on developing the rural pre-school education. Preschool education to the children's habits, intellectual development and physical and mental health is of great significance. Follow the rules of children's physical and mental development; adhere to the scientific method of wang security happy children healthy growth" [1]. Scientific physical exercise is the most direct and most effective way for children to improve physical and mental health, strengthen the system, and improve immune ability. The development situation of rural children body quality Leshan yi region are closely relsted with the development of the society, the backward economy yi region. Current situation of rural kindergarten sports activities in the region are studied to help the region's rural preschool physical education in such aspects as education concept, content, design get substantial sublimation.

\section{Research object and research method}

\subsection{Object of study}

Based on 4 kindergarten of Mabian county, township and Gao Zhuo camp township, the greater BaoXiang, 4 kindergarten of old dam township, ebian county were sleep mo village, song village, le wu township, township flat, a total of 8 kindergarten as the research object; randomly 2 teachers Each kindergarten were chosen as the investigation object.

\subsection{Research methods}

\subsubsection{Literature}


In order to understand the situation of rural preschool in leshan yi district sports research present, the main access to the China journal full-text database, ten thousand such as database and leshan relevant policies and regulations of the local government.

\subsubsection{Questionnaire investigation}

According to the needs of the research, design the yi region rural children sports status quo survey questionnaires, 80 questionnaires were distributed to the object of study, and recovery of 80 questionnaires, the recovery rate of $100 \%$. After the examination, 78 valid questionnaires, the effective rate was $97.5 \%$.

\subsubsection{Data statistics}

Use SPSS12.0 statistics software version of the social questionnaire data statistics.

\section{Results and analysis of the study}

\subsection{Kindergarten system}

Without the development of education in ethnic minority areas, there is no leshan education of scientific development, leshan "short board" of education in ethnic minority areas, the difficulties of education in preschool education in national regions, to promote the rapid development of preschool education in national regions, in 2014, leshan launched "takes a young" construction in national regions plan [2]. The nature of the leshan yi region rural kindergarten are made by the local government or education department responsible for the management of the public kindergarten, is mainly a village, set up a kindergarten, school size is small.

\subsection{Attention paid by parents (guardian) attaches to the situation of sports activities}

Children's understanding of sports knowledge directly affected by its parents on the sports knowledge and awareness, investigation (table 1) found that present yi region rural parents understanding of sports, attention is in the middle level, emphasis and above accounted for about a third of the total. The reason is parents education level, rapid economic development and living costs rise sharply, the parents excessively focus on cultural knowledge, insufficient understanding of physical and mental health. They think every day walk and run in the countryside, mountain can achieve physical exercise.

Table 1 parent awareness of sports knowledge and capabilities

\begin{tabular}{cccc}
\hline Very High & High & Normal & Low \\
\hline $8.3 \%$ & $20.1 \%$ & $40.5 \%$ & $31.1 \%$
\end{tabular}

\subsection{Analysis of sports venues and equipment for children}

The kindergarten work procedures stipulated in the kindergarten should match the size of the outdoor activity space, equipped with necessary games and sports facilities, and create conditions for preventing sand, animal feeding angle and plant garden, should be based on the characteristics of the kindergarten, greening, landscaping garden [3]. According to the survey (see table 2), in the countryside, outdoor sports venues can basically meet the needs of the sports teaching; while indoor space and large sports equipment, in particular, $10 \%$ of the total; Kindergarten is just set up soon, there are scattered equipment, but these small equipment can fully meet the needs of the class, the exchange of widespread use.

Table 2 rural children sports venues and equipment

\begin{tabular}{cccccccc}
\hline \multicolumn{2}{c}{ Outdoor playground } & \multicolumn{2}{c}{ Indoor stadium } & \multicolumn{2}{c}{ Sets of large equipment } & \multicolumn{2}{c}{ Small equipment } \\
Yes & No & Yes & No & Yes & No & Yes & No \\
\hline $90 \%$ & $10 \%$ & $10 \%$ & $90 \%$ & $10 \%$ & $90 \%$ & $100 \%$ & $0 \%$ \\
\hline
\end{tabular}




\subsection{Sports teaching content opened in the kindergarten}

\begin{tabular}{ccccccc}
\multicolumn{7}{c}{ Table 3 Children sports content list } \\
\hline Sports games & gymnastics practice & ball sports & equipment & special physical & quality & others \\
$78.3 \%$ & $85.1 \%$ & $28.3 \%$ & $61.5 \%$ & $10 \%$ & $20 \%$ & $18.5 \%$ \\
\hline
\end{tabular}

As shown in table 3, on the arrangement of the sports activities are stretched, lack of features, enrich 1:00 equipment of kindergarten is given priority to with sports games and basic baby gym, poor kindergarten with basic baby gym is given priority to, combined with the equipment design content accounted for more than $60 \%$, but in the ball, special sports activities, etc., all the content and frequency of the kindergarten practice is poor. The reason is on the one hand, teachers' teaching level is limited, without learning sports related knowledge; On the other hand is the restriction of the location equipment.

\subsection{Organization form of kindergarten sports}

How to attract children's attention and cultivate their interests and hobbies, mainly means to use what mode of transmission, to cultivate children's lifelong sports consciousness, adopt what kind of way to teach is crucial. Survey (table 4) found that sports activity is very single, made up of morning exercise, outdoor activities and indoor activities, setting-up exercises and the basic content, while special sports activities, the reason is rural kindergarten students basically unregular procession, age differences lead to different capacity, young children's safety problems; many teachers less, less equipment, sports teaching organization difficult; another problem due to the establishment of teachers without enthusiasm, not all problems, the other is not important, sports dispensable, read more, or can count most. These reasons lead to form single sports teaching, the teaching effect is not obvious, directly affect the quality of sports teaching.

Table 4 kindergarten teaching organization

\begin{tabular}{ccccc}
\hline Morning exercise & Outdoor sports & Indoor sports & Hiking & Children's sports \\
$80 \%$ & $90 \%$ & $80 \%$ & $20 \%$ & $10 \%$ \\
\hline
\end{tabular}

\subsection{Kindergarten sports teachers}

Leshan city bureau of education take "public recruit some formal teacher, muddleheaded, a group of primary school teachers, hiring a part of substitute teachers, village officials and volunteers in the part-time teachers", formed the yi region rural preschool teachers. Survey (table 5) show that sports teachers contact very little the preschool physical education professional knowledge before or after work, there are very few teachers through network and books to learn more part of the sports knowledge. At the same time, the teachers will not accept professional training or retraining, which lead to children's physical activity curriculum, teaching methods and so on can't intuitive, accurate, this is the most direct factors affecting the development of children's physical and mental health.

Table 5 Leshan yi region rural kindergarten professional sports teachers

\begin{tabular}{cc}
\hline Part-time sports teachers & Professional teachers \\
\hline $100 \%$ & $0 \%$ \\
\hline
\end{tabular}

\section{Conclusion and suggestions}

\subsection{Conclusion}

3.1.1 Leshan yi region is the main forms of public on rural kindergarten are almost all small scale of school. 
3.1.2 Parents of kindergarten are of low awareness of physical education, little emphasis, the more the economy lags behind, and the more serious the phenomenon is.

3.1.3 Brought to the attention of the local function administrative department level and economic condition restriction, kindergarten sports venues and a large sports equipment is very lack.

3.1.4 Rural preschool teachers' lack of ability of physical education major, the restriction of space equipment lead to children's sports content furtile, not adapt to children's physical development and all age groups.

3.1.5 Students class construction of system, teaching environment and teaching problem in kindergarten in yi areas of rural children's sports course teaching form is single, the teaching effect is not obvious.

3.1.6 Teacher's professional ability will directly lead to the education of sports education function failure, children's physical development.

\subsection{Suggestions}

3.2.1 Local government and the social various aspects focus on yi district rural kindergarten economic support

Take the big rural poverty requirement as an opportunity to improve the quality of education. The first is the local government increased investment in the economy of rural kindergarten. The follow by multi-channel funding by social folk organization in yi areas rural kindergarten, such as attract private capital investment by named after some rural kindergarten. Finally from the reality of district and township, actively advocate counterpart support local enterprises sponsored large sports equipment. Through the above the government investment, private financing, financing, investment and sponsorship to promote rural kindergarten in leshan yi campus facilities and the enrichment of teachers, for rural children's physical and mental health development to lay a solid foundation and creating good conditions.

3.2.2 Attaches great importance to the participation of parents to raise awareness of children's sports Teachers according to the actual situation of students' parents, especially parents, education degree of sports awareness is not high. Kindergarten can regularly organize outdoor parent-child activities in each semester, small games to open classes and sports activities, require parents with young children to participate in such activities, to help parents understand sports, knowledge, experience and cognition to the function of sports, to realize sports activities with children health of body and mind development is an organic whole will be inseparable relationship. Parents participate in the process can not only master the parent-child education skills and experience, they can also understand the child's development, strengthen the function of the parents, promote the development of children.

\subsubsection{Strengthen children's sports activities teacher connotation construction}

Local education department and the kindergarten send children sports instructor to participate in a variety of pre-employment professional sports skills, medium-term short-term training courses and professional learning. For example, regular visits to the educational condition good kindergarten to learn and to leshan teachers college professional studies, etc. Learn basic theory of children's sports, children's sports psychology, the kindergarten education activities design and guiding, etc. [4]. In order to improve teachers' professional technical level and teachers' teaching ability for the children's game of the plait method, grasp every activity exercise can improve all these aspects. Secondly, can introduce professional sports teachers in kindergarten, the local education department given on preparation and tilt, in order to solve the introduction of talent, to prevent the loss of talent, to solve the trouble back at home of teachers, to adjust the structure of yi region rural kindergarten teachers, injected fresh blood, the introduction of advanced scientific education concept and 
teaching method, promote the professional development of teachers, improve the quality of teaching. Finally is to organize the teacher view excellent children's sports model lesson, good teachers teach them methods of advanced teaching organization, teaching design and teaching evaluation methods, to understand and grasp the good teaching methods and education concept, scientific and reasonable design and organize activities of physical education, closely combine with children's physical and mental health law of development.

3.2.4 Positive innovation, adjust measures to local conditions of the rich sports teaching content

Folk, is formed by the people in the long life of common customs and ways [5]. Make full use of the rich resources of national characteristics of the ethnic minorities, conduct positive innovation yi folk dances, games, and young children's basic gymnastics. Folk sports game is given priority to with found that removing the sex and flexibility, more for heritage, folk sports activities to improve, such as gyro, walking on stilts, the game forms popular rural children's favorite, has strong exercise value and entertainment function. At the same time some folk games also have considerable education function, such as the hopscotch. Material: chalk, plastic pieces, a piece of flat land, picture corresponding grid on the ground, then divide the students into 2 to 6 people around corresponding group number, hop, tiptoe kicks plastic block, a corresponding number. The function of education, choose the suitable plastic block, good effort size control, strength, right Angle, patience to play. Such games for children's leg strength enhancement; Coordination and sensitivity of development; the ascension of willpower and the unity cooperation consciousness training, for ethnic minority areas folk activities, make full use of the mining effects strengthen physical health, mental and physical health, cultural heritage has a promoting role.

\section{Summary}

The local education departments strengthen the regulation of children's sports teaching kindergarten. Regular or irregular supervision of teaching to check the teaching file packet data is complete or not. And check of teaching content. Check the conditions of the local sports teaching hardware facilities according to the actual yi region rural natural conditions at the same time. On the basis of scientific and practical, adjust measures to local conditions to revise a kindergarten school year, semester sports teaching activity design and safety; content of infant health evaluation indicators and methods; preschool physical education teaching activities of the evaluation system of professional evaluation, so as to gradually achieve relevant indicators of leshan rural kindergarten sports activities of the, gradually achieve leshan yi region rural children sports, health, science and lasting development in an all-round way.

\section{Acknowledgements}

"Sichuan Province Key Research Institute of Humanities and Social Sciences, higher school of rural preschool education research center" 2013 general project "under the background of Yi culture research and sports activities of rural preschool - a case study of Leshan city" (project number: NYJ2013061).

\section{References}

[1] The national medium and long-term education reform and development plan outline. [J].2014.

[2] A kindergartn for each village to realize nationality development in leshan construction. [J].2013

[3] The kindergarten work procedures at http://www.bjchy.gov.cn/affair/zfyj/law/15365.htm. 
[4] RanJian, etc., the Hong Kong and Macao district preschool physical education research and enlightenment to the mainland [J]. Journal of Chengdu sports institute, 2015.

[5] Zhu Guoquan. "Traditional sports culture" [M]. Sichuan University press, $2013 .$. 